Rev Inv Vet Perú 2003; 14 (2): 150-154

\title{
SEROPREVALENCIA DE Neospora caninum EN CANINOS DE DOS DISTRITOS DE LA PROVINCIA DE CHACHAPOYAS
}

\author{
Segundo Horna M. ${ }^{1}$, Amanda Chávez V. ${ }^{2,3}$, Eva Casas A. ${ }^{2}$ y \\ Enrique Serrano M.
}

\section{AbSTRACT}

Neospora caninum is a parasite of dogs that causes high rates of abortion and neonatal mortality in cattle throughout the world. The objective of the study was to determine the prevalence of Neospora caninum in dogs from districts of Molinopampa and Leymebamba, province of Chachapoyas, Amazonas. A total of 142 serum samples were evaluated (63 from Molinopampa and 79 from Leymebamba) for the detection of antibodies using the indirect immunofluorescence test (IFAT). The $28.9 \pm 7.5 \%$ of the animals were positive to $N$. caninum. A seroprevalence of $34.9 \pm 11.8 \%$ and $24.1 \pm 9.4 \%$ were found in dogs of Molinopampa and Leymebamba districts, respectively. This results demonstrate the existence of a high seroprevalence of dogs infected with Neospora caninum in the region.

Key words: dogs, Neospora caninum, abortion, IFAT, neosporosis, tropical forest

\section{Resumen}

El Neospora caninum, parásito del canino, es ampliamente conocido como causante de abortos y mortalidad neonatal en bovinos a nivel mundial. El objetivo del presente estudio fue determinar la seroprevalencia de $N$. caninum en caninos de los distritos de Molinopampa y Leymebamba, provincia de Chachapoyas, Amazonas. Se evaluaron 142 sueros de caninos (63 de Molinopampa y 79 de Leymebamba) para la detección de anticuerpos mediante la prueba de Inmufluorescencia Indirecta (IFI). El 28.9 $\pm 7.5 \%$ de los caninos presentaron anticuerpos contra $N$. caninum. Seroprevalencias de $34.9 \pm 11.8 \%$ y $24.1 \pm 9.4 \%$ fueron halladas en caninos de los distritos de Molinopampa y Leymebamaba, respectivamente. Estos resultados demuestran la existencia de una seroprevalencia moderadamente alta de caninos infectados $\operatorname{con} N$. caninum en la región estudiada.

Palabras clave: caninos, Neospora caninum, abortos, IFI, neosporosis, selva alta

\footnotetext{
${ }^{1}$ Práctica privada

${ }^{2}$ Laboratorio de Microbiología y Parasitología Veterinaria, FMV-UNMSM

${ }^{3}$ E-mail: a_chavez_g@hotmail.com
} 


\section{INTRODUCCIÓN}

El poblador alto andino convive con los perros, quienes llegan a ser parte integrante de la familia; desde simples animales de compañía hasta guardianes de la casa y pastores de los animales de producción.

Por otro lado, los caninos juegan un rol importante en la transmisión de diversas enfermedades a los bovinos, entre ellas la neosporosis. El perro se reconoce como el único hospedero definitivo del parásito Neospora caninum (McAllister et al., 1998) y es considerado como potencial transmisor del parásito, toda vez que los perros se encuentran en los establos y en zonas de crianza extensiva (Wouda et al., 1999; OrtegaMora et al., 2001).

La neosporosis ha adquirido gran importancia a nivel mundial por tener altos índices de prevalencia y estar considerada como una de las principales causas de aborto bovino (Dubey y Lindsay, 1996). Aunque el aborto es el efecto más adverso de la infección, se debe tomar en cuenta otras repercusiones, tales como la reducción en el número de terneros, mayor número de inseminaciones, repetición de celos, baja de la producción de leche y el sacrificio prematuro o venta de animales infectados, los cuales ocasionan grandes pérdidas económicas en la industria ganadera (Ortega et al., 2001)

Estudios de prevalencia en el Perú indican que esta infección está presente en bovinos de las principales cuencas lecheras [57\% en Arequipa (Andresen, 1999); 42.9\% en Cajamarca (Cabrera et al., 2000); 29.6\% en Lima (Silva, 2002); $40 \%$ en Amazonas (Quevedo, 2003]. En perros de establos lecheros de Lima se encontró una frecuencia de 32.7\% (Del Campo, 2003).

Dada la prevalencia de $N$. caninum observada en bovinos de crianza extensiva de la provincia de Chachapoyas, Amazonas, se consideró necesario complementar la in- formación existente con un estudio de seroprevalencia en caninos a fin de tener un mejor conocimiento de la epidemiología de la enfermedad en el país.

\section{Materiales y Métodos}

\section{Lugar de estudio}

El estudio se ralizó en los distritos de Molinopampa y Leymebamba, provincia de Chachapoyas, departamento de Amazonas, ubicados sobre los 2,200 msnm. El área presenta una topografía accidentada con zonas de cordilleras y valles interandinos, clima templado, moderadamente lluvioso, con temperatura que oscila entre 10 y $28^{\circ} \mathrm{C}$, y con estaciones climáticas diferenciadas de seca (mayo a agosto) y lluvia (septiembre a abril) (INEI, 2002). La actividad primaria es la ganadería de doble propósito no especializada.

\section{Animales y tamaño muestreal}

Se muestreó caninos procedentes de 11 fundos ganaderos de Molinopampa y 13 fundos de Leymebamba, así como de caseríos de ambos distritos. Se consideró como caninos de fundos ganaderos a los que viven en el mismo fundo, mientras que se consideró como caninos de los caseríos a los que viven en las casas de la zona urbana de los distritos y que eventualmente transitan por los fundos ganaderos.

El tamaño muestral se obtuvo mediante el método de muestreo aleatorio simple para poblaciones finitas basados en el cálculo de la población canina. Se determinó un tamaño muestral de 130 animales.

\section{Muestras y detección de anticuerpos contra Neospora caninum}

Las muestras se sangre se colectaron en junio del 2002, por punción directa de la vena cefálica. Los sueros resultantes se colocaron en microviales estériles y almacenados 
en congelación a $-20{ }^{\circ} \mathrm{C}$ hasta su análisis en el Laboratorio de Parasitología Veterinaria de la Facultad de Medicina Veterinaria de la Universidad Nacional Mayor de San Marcos.

Se utilizó la prueba de inmunofluorescencia indirecta (IFI) para determinar anticuerpos contra Neospora caninum. Se usó una dilución de 1:50 utilizando como antígeno a taquizoítos formalizados (Cepa Nc1) y congujado comercial VMRD-USA.

\section{Análisis de datos}

La prevalencia de Neospora caninum en los distritos bajo estudio se estimó mediante la fórmula de Thrusfield (1990).

Las variables edad, sexo y procedencia geográfica de las muestra se evaluaron con respecto a la presencia de anticuerpos de Neospora caninum en perros, mediante la prueba de Regresión Logística usando el programa SPPS 10.0.

\section{Resultados y Discusión}

La seroprevalencia de Neospora caninum hallada en los caninos de los distritos de Molinopampa y Leymebamba fue de $28.9 \pm 7.5 \%$ (Cuadro 1); frecuencia similar a la reportada para caninos de establos lecheros del valle de Lima (Del Campo, 2003), donde se consideró que la prevalencia de caninos podría estar ligada a la seroprevalencia en bovinos. Con los resultados hallados en el presente estudio y comparados con la prevalencia de $40 \%$ encontrada en bovinos de la zona por Quevedo (2003), se estaría demostrando la estrecha relación existente entre el canino y el bovino en la zona de Chachapoyas.

Los resultados observados en este estudio, al igual que en el estudio de Quevedo (2003) en bovinos, muestran niveles de seroprevalencia de $N$. caninum relativamente superiores para los animales de Molinopampa con relación a Leymebamba, aunque los análisis estadísticos no demostraron que el distrito sea un factor de riesgo para adquirir la enfermedad. Estos resultados podrían deberse al efecto de contacto de los caninos con los bovinos si se considera que los fundos en Molinopampa están alrededor de los caseríos a diferencia de los fundos de Leymebamba que están a dos horas de camino. Asimismo, se sabe que en el distrito de Molinopampa se introdujeron mayor número de reproductores de raza Brown Swiss procedentes, tanto de Cajamarca como de Lima, donde la prevalencia de Neospora caninum es alta, y posiblemente fueron los bovinos quienes introdujeron este parásito e infectaron la zona.

Los valores de seroprevalencia de Neospora caninum encontrados, según sexo, edad y procedencia (Cuadro 2) son muy similares. La prueba de regresión logística demostró que no representan factores de riesgo para adquirir la enfermedad. Lindsay et al. (1999) en USA tampoco hallaron diferencias con respecto al sexo en caninos que manifestaban sintomatología clínica. La edad de los caninos no mostró variación en la seroprevalencia, lo que significaría que la transmisión horizontal no tendría mucha importancia en la epidemiología de la enfermedad.

Los caninos procedentes de fundos presentaron una seroprevalencia relativamente superior al de los caninos procedentes de los caseríos. Asimismo, se reconoce que los canes de los fundos ganaderos se crían con un nivel sanitario y alimentario no controlado, encontrándose más propensos a ingerir fetos abortados y/o placentas; por lo que estarían más expuestos a adquirir infecciones que aquellos criados en casas. Esto ha sido demostrado en San Paulo, Brasil, en perros de la calle con condiciones sanitarias y alimentarias deficientes comparados con canes de domicilios con condición sanitaria media (Belo et al., 1999). 
Cuadro 1. Seroprevalencia de Neospora caninum en caninos de dos distritos de la provincia de Chachapoyas, Amazonas. 2002

\begin{tabular}{lcccccc}
\hline \multirow{2}{*}{ Distrito } & $\begin{array}{c}\text { Animales muestreados } \\
\text { (n) }\end{array}$ & $\begin{array}{c}\text { Animales positivos } \\
\text { (n) }\end{array}$ & \multicolumn{3}{c}{$\%$} & $\pm \mathrm{IC}^{1}$ \\
\hline Molinopampa & 63 & 22 & 34.9 & \pm & 11.8 \\
Leymebamba & 79 & 19 & 24.1 & \pm & 9.4 \\
\hline Total & 142 & 41 & & 28.9 & \pm & 7.5 \\
\hline${ }^{1}$ Intervalo de confianza del 95\% & & & & & &
\end{tabular}

Cuadro 2. Seroprevalencia (\%) de Neospora caninum en caninos de la provincia de Chachapoyas, Amazonas, distribuidos según sexo, edad y procedencia. 2002

\begin{tabular}{|c|c|c|c|c|c|}
\hline \multicolumn{2}{|c|}{ Sexo } & \multicolumn{2}{|c|}{ Edad } & \multicolumn{2}{|c|}{ Procedencia } \\
\hline Hembra & Macho & $<1$ año & $>1$ año & Fundo & Caserío \\
\hline $24.6 \pm 5.5$ & $32.1 \pm 10.2$ & $31.4 \pm 15.4$ & $28.0 \pm 8.5$ & $32.0 \pm 10.3$ & $25.4 \pm 10.4$ \\
\hline $15 / 61$ & $26 / 81$ & $11 / 35$ & $30 / 107$ & $24 / 75$ & $17 / 67$ \\
\hline
\end{tabular}

Adicionalmente, se sabe que los fundos de la zona en estudio han venido realizando trabajos de mejoramiento genético mediante la introducción de reproductores de raza Brown Swiss procedentes de Cajamarca, Lima y Trujillo; de allí que la neosporiasis haya venido siendo introducida en forma paulatina. Estudios recientes de $N$. caninum en bovinos del valle de Cajamarca y en Lima indican una seroprevalencia de $43 \%$ (Cabrera et al., 2000) y $30 \%$ (Silva, 2002), respectivamente.

Se sospecha que la fuente de ingreso de este parásito en bovinos de la cuenca lechera de Lima sería a través de la introducción de canes de razas puras, quienes son importados sin mayores exigencias sanitarias (Del Campo, 2003); sin embargo, esta posibilidad resultaría muy remota en la cuenca lechera del Amazonas, donde no es frecuente la introducción de caninos de otro lugares para el cuidado de los bovinos. Además, en el presente estudio solo se hallaron caninos nativos, en su mayoría cruzados.

\section{Conclusiones}

- Se encontró una seroprevalencia moderadamente alta $(28.9 \pm 7.5 \%)$ de caninos que fueron infectados con Neospora caninum en los distritos de Molinopampa y Leymebamaba de la Provincia de Chachapoyas, Amazonas.

- La edad, sexo y procedencia (fundo, caserío y distrito) no representaron factores de riesgo para a adquirir la enfermedad. 


\section{Literatura CitadA}

1. Andresen, H. 1999. Neosporosis en el Perú y el mundo. Rev. Cienc. Vet. 15:1114, 30-31.

2. Belo, M.A.A.; P.C.B. Rezende; K.C. Castagnolli; K.D.S. Bresciani; A.J. Costa. 1999. Pesquisa de anticorpos anti-Neospora caninum em câes criados sob diferentes condições sanitarias. XI Seminario Brasileiro de Parasitología Veterinaria. p 228.

3. Cabrera, M.; P. Ortiz; J. Claxton; D. Williams; A. Trees. 2000. Evidencia serológica de infección por Neospora caninum en ganado vacuno en Perú. IV Congreso Peruano de Parasitología. $\mathrm{p}$ 212.

4. Del Campo, J.F. 2003. Frecuencia de Neospora caninum en perros de establos lecheros del valle de Lima. Tesis de Médico Veterinario. Facultad de Medicina Veterinaria, Univ. Nacional Mayor de San Marcos, Lima. 52 p.

5. Dubey, J.P.; D.S. Lindsay. 1996. A review of Neospora caninum and neosporosis. Vet. Parasitol. 67: 1-59.

6. INEI. 2002. Directorio Nacional de Municipalidades Provinciales, Distritales y de Centro Poblado Menor. Lima. p 17.

7. Lindsay, D.S.; J.P. Dubey; M.M. McAllister. 1999. Neospora caninum and the potential for parasite transmition. Pract. Vet. 21: 317-321.

8. McAllister, M.M.; J.P. Dubey; D.S. Lindsay; W.R. Joley; R.A. Wills; A.M. Mc Guire. 1998. Dogs are definitive hosts of Neospora caninum. Int. J. Parasitol. 28: 1473-1478.

9. Ortiga-Mora, L.M.; E. Collantes; G. Alvares. 2001. La neosporosis del ganado bovino: Una enfermedad emergente. Rev. Cien. Vet. 17: 7-14.

10. Quevedo, J.M. 2003. Neosporosis en bovinos lecheros en dos distritos de la provincia de Chachapoyas. Tesis de Médico Veterinario. Facultad de Medicina Veterinaria, Univ. Nacional Mayor de San Marcos, Lima. 63 p.

11. Silva, P. 2002. Seroprevalencia de Neopora caninum en bovinos lecheros del valle de Lima. Tesis de Médico Veterinario. Facultad de Medicina Veterinaria, Univ. Nacional Mayor de San Marcos, Lima. 42 p.

12. Thursfield, M. 1990. Epidemiología Veterinaria. p 228-230. Ed. Acribia. España.

13. Wouda, W.; Th. Dijkstra; A.M.H. Kramer; C. Van Maanen; J.M.A. Brinkfhof. 1999. Seroepidemiological evidence for relationship between Neospora caninum in dogs and cattle. Int. J. Parasitol. 29: 1677-1682. 